Bartın Üniversitesi

Eğitim Fakültesi Dergisi

Cilt 6, Sayı 3, s. 1249 - 1263, Ekim 2017 BARTIN - TÜRKIYE

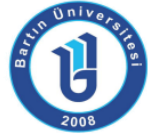

ISSN: 1308-7177
Bartin University

Journal of Faculty of Education

Volume 6, Issue 3, p. 1249 - 1263, October 2017

BARTIN - TURKEY

Doi: 10.14686/buefad.335904

\title{
Öğretmen Adaylarının Epistemolojik İnançlarının Problem Çözme Becerileri ve Güçlülük Düzeyleri Üzerine Olan Etkisinin İncelenmesi
}

Miray ÖZÖZEN DANACl, Öğr. Gör, Düzce Üniversitesi Sağlık Hizmetleri Meslek Yüsekokulu, mirayozozen@hotmail.com, ORCID: http://orcid.org/0000-0002-6993-9038

Özge PINARCIK, Yrd. Doç., Düzce Üniversitesi, o_pinarcik@hotmail.com

Öz: Epistemolojik inanç, bireyin yeni karşılaştıkları bilgileri işleme ve yorumlama biçimleri, kavrama düzeyleri, çalışma stratejileri, üst düzey düşünme becerileri gibi değişkenler üzerinde belirleyici etkilere sahiptir. O halde eğitimde önemli rol üstlenen öğretmen adaylarının bilgiye ulaşma ve bilgiyi elde etme durumlarını etkileyebilecek olan problem çözme ve güçlülük düzeyleri üzerinde epistemolojik inançlarının ne şekilde etkili olabileceği bu araştırmanın problemini oluşturmaktadır.

Araştırmanın çalışmanın grubunu Düzce Üniversitesi Okul Öncesi Öğretmenliği Bölümü’nde öğrenim gören 80 kız ve 70 erkek olmak üzere toplam 150 öğretmen adayı oluşturmaktadır. Iliş̧isel tarama modeli ile yürütülen çalışmada, veri toplama araçları olarak 'Kişisel Bilgi Formu' ile Rosenbaum (1980) tarafından geliştirilen 'Rosenbaum Öğrenilmiş Güçlülük Ölçeğl', Heppner ve Petersen (1982) tarafından geliştirilen 'Problem Çözme Envanteri' ve Schommer (1990) tarafından geliştirilen 'Epistemolojik (Bilgibilimsel) İnanç Ölçeği' kullanılmıştır.

Çalışma, epistemolojik inançları gelişmiş bireylerin problem çözme ve güçlülük düzeylerinin de benzer doğrultuda yüksek olduğunu göstermektedir. Bu noktada özellikle psikolojik olarak yıpratıcı ve sarsıntılı biçimde olumsuz durumlara maruz kalan bireylerin problem çözme ve güçlülük becerilerinin güçlendirilmesi için epistemolojik inançlarının desteklenmesi ve bu hedefe yönelik sağaltım süreçleri uygulanması yerinde olacaktır.

Anahtar Kelimeler: Öğretmen, epistemolojik inanç, problem çözme, güçlülük

\section{An Analysis of the Effects of Teacher Candidates' Epistemological Beliefs on Problem Solving Skills and Levels of Power}

Abstract: The epistemological belief is based on variables such as the way in which the individual processes and interprets the information they meet, their level of comprehension, their working strategies, and their ability to think at higher levels have decisive effects. The problem of this research is therefore how the epistemological beliefs on the levels of problem solving and empowerment that may affect the availability of knowledge and knowledge of prospective teacher candidates playing an important role in education constitute the problem.

The study group of the study is composed of 80 female and 70 male students who are studying at Düzce University Preschool Teaching Department. The 'Rosenbaum Learned Achievement Scale' developed by Rosenbaum (1980) and the 'Problem Solving Inventory' developed by Heppner and Petersen (1982) and 'Epistemological Belief Scale' developed by Schommer (1990) was used for data collection tools.

The study shows that the level of problem solving and empowerment of individuals who have developed epistemological beliefs is also high in a similar direction. At this point, it would be appropriate to support epistemological beliefs and apply treatment to this goal in order to strengthen the problem solving and strength skills about individuals who are particularly exposed to psychologically depressing and jarringly negative situations.

Key Words: Teacher, epistemological belief, problem solving, powerfulness 


\section{GíRiş}

İnsanı diğer canlılardan ayrılan en önemli özelliği aklıdır. Inssanın düşünebilen, araştırabilen, sorgulayabilen bir varlık olması aklı sayesinde gerçekleşir. Bunun sonucu olarak da insan bilme ihtiyacı duyar ve ürün olarak "bilgi” ortaya çıkar. Ortaya çıkan bu bilgi, insanın hayatta kalmasını ve doğaya uyumunu sağlar. Zamanla insanoğlu bilgiyi doğaya uyumdan farklı olarak doğaya yön verme amacıyla kullanmıştır. Yine de bilgi kavramı insanlar için hep düşündürücü olmuştur. İnsan bilginin ne olduğu, doğru bilgiye ulaşılıp ulaşılamayacağı, bilginin değerini, kaynağını, geçerliliğini, sınırlılı̆̆ını araştırmak istemiştir.

Epistemoloji, kısaca bilgiyi ele alan, bilgi ile ilgili problemleri araştıran bir felsefe disiplini ortaya çıkmıştır. Bilgi felsefesi veya epistemoloji olarak adlandırılan bu disiplin, genel olarak bilginin ne olduğunu, nasıl ve ne yoldan elde edildiğini konu edinir (Çüçen, 2005). Felsefenin temel alanlarından biri olan epistemoloji esas olarak insan bilgisinin doğasını, kaynaklarını, sınırlarını, kavramsal bileşenlerini ve hatta bilginin olanaklı olup olmadığını irdelemektedir (Külcü, 2000). Epistemoloji, kendisine konu edindiği bilimin hedeflediği şeylerden tamamen soyutlanmakla uğraşmaktadır. Böylece epistemoloji, bilgileri artırmak ya da yıldızların veya evrenin gözlemlenmesi gibi yepyeni deneysel sahaları keşfetmekle hiçbir şekilde ilgilenmemektedir. Epistemoloji, aslında sınırları belirlenmiş dört analiz ve düşünme alanı sunmaktadır:

1. Bilimsel teori ve kavramların yapısı ve niteliği. Buna bazen teorilerin sentaksı da denmektedir;

2. Bilimsel teori ve kavramların kapsamı ve konusu. Buna benzer şekilde teorilerin semantiği de denmektedir;

3. Bilimsel metot;

4. Bilimsel teşebbüsün değeri ve sınırlarıdır.

Modern bilim dallarının çalışma alanlarının her birinin temelinde, inceledikleri alanlara dair bilgi edinmek, açıklamak ve elde edilen bilgilerin uygulamalarını gözlemlemek yer almaktadır (Giancoli, 2003. Felsefenin de bilgiyi incelediği alan felsefe literatüründe epistemoloji olarak geçmektedir. Epistemoloji, çeşitli bilimlerin prensiplerinin, hipotezlerinin ve sonuçlarının mantıksal kökenini, değerini ve objektif kapsamını tespit etmek" istemektedir (Virieux, 1966; Simard, 2003).Hofer, Pintrich (2002) epistemolojiyi insan bilgisinin kaynağı, doğası, sınırılıkları, sistemi ve doğruluğu olarak tanımlamaktadır. Bilgi kuramının kurucuları arasında yer alan Locke (1952)'e göre bilgi kuramı, bilginin kökenini, doğruluğunu ve sınırlarını, buna göre de inanç, kanı ve yargılarımızın derece ve temellerini araştırır (Kale, 2009). Buradan hareketle epistemolojinin en can alıcı problemleri olan "ne" biliyorum?" ve "nasıl biliyorum?" sorularının temelini oluşturan diğer sorular ise, "bilgide kesinliğe nasıl ulaşabiliyorum" ve "bilgileri nasıl doğrulayabiliyorumdur". Bu noktada ise epistemoloji bireyin öğrenme sürecinde konumlandırıldığında, öğrenmenin mantıksal çözümlemeler ve güçlülük-kolaylık gibi değişkenleri etkileyebildiği düşünülmektedir.

Bireylerin yetenek düzeyi, benlik saygısı, kendine güven, öz yeterlilik algıları, başarı ya da başarısızlık yüklemeleri, denetim odağı ve epistemolojik inançlar gibi bireysel özelliklerin öğrencilerin bilişsel mantıksal çözümleme stratejilerini kullanmalarında ve öğrenmelerinde, dolayısıyla eğitim sektöründe belirleyici etkileri olduğu yönünde güçlü kanıtlar ifade edilmiştir (Garner, 1990; Garner, Alexander, 1989; Jonassen, Grabowski, 1993; Main, Rowe, 1993; Osman ve Hannafin, 1992).

Birey, öğrenme esnasında sözel tekrar, altını çizme, not alma, özetleme, soru oluşturma ve ya konuların ana hattını ortaya koyma şeklinde farklı türlerde ve düzeylerde zihinsel öğrenme stratejilerini kullanırlar. Bu stratejilerin ana işlevi, yeni bilgiler ile öğrenilmiş 
bilgilerin ilişkilendirilmesini sağlamaktır. Böylece bilgi belleğe kodlanabilmektedir. Bilgiyi işleme sürecinde bireyin, verimli ve etkili stratejiyi araştırması ve denetlemesi ise metabiliş kavramı ile açıklanmaktadır (Derry, 1990). Araştırmalar, başarılı olan ve başarısız olan öğrenciler arasındaki ilk ve önemli farkılığın, başarısız öğrencilerin bireysel kavramalarını denetlemelerindeki yetersizlikler olduğunu ortaya koymuş ve metabiliş yeteneğine dikkat çekmiştir (Derry, 1990; Paris, Myers, 1981). Bu noktada ise metabiliş yeteneğinin en önemli kilit noktaları ise problem çözme becerisi ve güçlülüktür.

Problem çözmenin herhangi bir zorluk durumuyla karşılaşıldığında bu durumdan güçlü bir şekilde çıkmayı sağlayan bir kapasite olması, güçlülüğün ise, bu zor ve yıpratıcı koşullarda dahi geleceğe yönelik olumlu bir bakış açısına sahip olabilme yeteneği olması ve her iki yeteneğin de davranışları yönlendirmesi epistemolojik inançlar ile olabilecek ilişkiyi düşündürmektedir.

Problem, genel itibariyle karşılaşılan güçlük olarak tanımlanabilir. Problem, bireyin amaçlanan hedefine ulaşabilmek için harcadığı güçlerinin önüne çıkabilen engel ve çatışma durumu şeklinde tanımlamaktadır (Morgan, 1999; Bingham, 1998). Problem çözme ise bu güçlüğün ortadan kaldırılmasıdır (Aksu,1990). Problem çözme becerisi, kişiyi çözüme götürecek bilgilerin kazanılması ve kullanıma hazır olacak şekilde birleştirilerek, bir sorunun çözümünü uygulayabilme düzeyidir (Ulupınar, 1997). Problem çözme becerisi, bilgi edinmede esastır. Problemi, çözen kişi bilgiye çabuk ulaşır. Epistemolojik inanç kavramında yer alan bilgiye ulaşma felsefesinin temelinde de bu durum yer almaktadır.

Öğrenilmiş güçlülük ise stresli yaşamsal olaylar ve problemlerle baş etmede bireye destek olabilen belli tutumları kapsamaktadır (Çakır, 2009). Yani, öğrenilmiş güçlülük bireyin stresle karşılaştıkları durumda bilinçle davranarak bu süreçten ne şekilde başarılı olarak kendini kurtarabildiğini açıklamaktadır (Dağ, 1991). Dolayısıyla öğrenilmiş güçlülük, stres yönetimi ve stresle baş etmede etkili ve nitelikli bir karakteristik beceri olarak ele alınmaktadır. Bu yönüyle de öğrenilmiş güçlülüğün bireylerin epistemolojik inançlarının hedeflerinde yer alan değişkenlerden etkilenebileceği düşünülmektedir.

Literatürde epistemolojik inançların ve problem çözmenin farklı durumlar ile olan ilişkileri üzerine yapılan araştırmalarda bu değişkenlerin akademik başarı, problem çözme becerisi, öğretim stilleri, cinsiyet ve sınıf düzeyi, yaş, akran ilişkileri sınıf, cinsiyet, aile yapısı, özyeterlilik, sınıf yönetimi, öğrenme stratejileri ve süreçleri ve benimsenen eğitsel felsefe örnek olarak verilebilir (Schommer, 1998; Chan, 2004; Rodriguez, Cano, 2007; Yükselen, Çetin, 2007; Boz, Aydemir ve Aydemir, 2011; Bedel, 2012; Trakulphadetkraia, 2012; Mohamed ve Habba, 2013). Ancak epistemolojik inançlar ile bireylerin metabiliş verimliliğinde kilit role sahip olan problem çözme becerisi ve öğrenilmiş güçlülüğün arasında olabilecek ilişkinin incelenmesi ile öğrenmenin felsefi boyutlarının yapılandırılması ve geliştirilmesine katkıda bulunulabileceği hedeflenmektedir.

\section{Yöntem}

\subsection{Araştırmanın Modeli}

Araştırma betimsel tarama modelinde ilişkisel tarama modelli olarak yürütülmüştür. Tarama modelleri geçmişte ve ya halen bulunan durumları var olan biçiminde tasvir etmeyi amaçlayan araştırma modelleri için uygundur (Karasar, 2006). İki ve daha fazla sayıda değişkenler arası değişimleri veya bu değişimlerin düzeyini tespit etmeyi hedefleyen tanımlayıcı nitelikteki araştırma modeli, eğitim fakültesi öğrencilerinin epistemolojik inanç düzeylerinin problem çözme becerisi üzerindeki etkisini belirlemek amacıyla ele alınmıştır. Gözlenmekte olan değişkenlere yönelik hatalara dikkat etmesi, çok değişkene sahip modelleri 
geliştirmeyi, yordama ve test etme sağlaması, modelin sahip olduğu değişkenler arası bağlantıların direkt ve ya dolaylı etkilerinde inceleme yapması sebebiyle çoğunlukla tercih sebebidir (Raykov, Marcoulides, 2006). Araştırma, birbirine bağımlı üç değişkenin korelasyonunun incelenmesi bakımından yapısal eşitlik modeli ile planlanmıştır.

\section{2.Çalışma Grubu}

Çalışmanın evrenini Düzce Üniversitesi Eğitim Fakültesi öğrencileri oluşturmaktadır. Örneklem grubunu ise 2015-2016 eğitim-öğretim yılında Düzce Üniversitesi Eğitim Fakültesi Okul öncesi öğretmenliği bölümünde öğrenim gören $80 \mathrm{kız}$ ve 70 erkek olmak üzere toplam 150 öğrenci oluşturmaktadır. Çalışma grubu seçkisiz örnekleme yöntemi ile seçilerek oluşturulmuştur.

\subsection{Veri Toplama Araçları}

Veri toplama araçları dört bölümden oluşmaktadır. Birinci bölümde öğretmen adaylarına yönelik demografik bilgileri içeren sorular yer almaktadır. İkinci bölümde Öğrenilmiş Güçlülük Düzeyi Ölçeği kullanılmıştır. Üçüncü bölümde Problem Çözme Envanteri kullanılmış ve dördüncü yani son bölümde ise Epistemolojik (Bilgibilimsel) Inanç Ölçeği kullanılmıştır.

\section{Rosenbaum Öğrenilmiş Güçlülük Düzeyi Ölçeği}

Orjinal formu Rosenbaum (1980) tarafından geliştirilen "Rosenbaum Öğrenilmiş Güçlülük Ölçeği" nin Türkçeye uyarlaması Siva ve Dağ (1991) tarafından yapılmıştır. Rosenbaum öğrenilmiş güçlülük ölçeğinin, öğrenilmiş güçlülüğün değerlendirilmesinde oldukça uygun bir araç olduğu araştırmalarla desteklenmiştir (Dağ, 1990). 36 maddeden oluşan ölçek, 5'li likert tipi şeklinde oluşturulmuştur. Ölçekte puanlar yükseldikçe, kendini denetleme becerilerinin yüksekliği, başa çıkma stratejilerinin sıklıkla kullanıldığına işaret etmektedir. Ölçek, 17 yaş ve üstü en az orta öğretim mezunu kişilere uygulanabilmektedir. Ölçeğin çevirisi Siva (1991) tarafından klinik psikoloji uzmanlarına danışılarak yapılmıştır.

Öğrenilmiş Güçlülük Ölçeğine ait 12 adet faktör bulunmuştur. Bu faktörler, planlı davranış, ruhsal denetim, istenmeyen düşüncelerin denetlenmesi, dürtüselliğin denetlenmesi ve planlı davranış, yeterlilik ve kendini sakinleştirme, ağrııı denetlenmesi, erteleme, yardım araştırma, iyi yorumlama, dikkat yönlendirilmesi, esnek plan ve teftiş eden arama olup çalışmada alt boyutlar kullanım dışı bırakılmış, ölçeğin tamamı değerlendirilmiştir.

Ölçeğin güvenirliği için hesaplanan Cronbach alfa kat sayısı .84' olarak bulunmuştur. Türkiye'de ölçekle ilgili geçmiş yıllarda yapılan çalışmalarda değerler, 78, 77, 75, 79, 83 olarak bulunmuştur (Dağ, 1991; Yıldırım, Ekinci, 2005; Dönmez, Genç, 2006; Yıldırım vd., 2007; Gazioğlu, Demir, 2008). Rosenbaum, Cohen (1999) araştırmalarında ölçeğe ait iç tutarlılık katsayısını 85 olarak ifade etmişlerdir. Sonuç olarak bu değerlere göre, ölçeğin güvenirlik değeri oldukça yüksek bir değer şeklinde ifade edilebilir.

\section{Problem Çözme Envanteri (PÇE)}

Problem Çözme Envanteri, Heppner, Petersen (1982) tarafından geliştirilmiş, bireyin problem çözme becerisine ilişkin kendini anlayabilmesini değerlendiren bir ölçektir. Olumluolumsuz ifadeler içeren ölçek likert tipi şeklinde 35 maddeden oluşmaktadır. Ölçekten elde edilen puanlardaki yükseklilik, bireyin problem çözme becerisini yetersiz görmesi anlamına gelmektedir. Ölçeğin Türkçe uyarlaması, Taylan (1990) ile Şahin, Şahin, Heppner (1993) tarafından yapılmıştır. Uyarlamada, ölçeğin 6 boyutan oluştuğu ve bu boyutların ise; aceleci yaklaşım, değerlendirici yaklaşım, kendine güvenli yaklaşım, düşünen yaklaşım, planlı yaklaşım olduğu ifade edilmiştir (Savaşır ve Şahin, 1997). Ölçekte yer alan alt boyutlar; 
Kaçıngan yaklaşım: Bireyin, sorunların çözümlenmesine ilişkin detaylı bilgi edinmeyi düşünüp düşünmediğinin ölçülmesidir.

Kendine güvenen yaklaşım: Problem çözmeye ilişkin bireyin özgüvene sahip olup olmadığının ölçülmesidir.

Değerlendirici yaklaşım: Bireyin problemle karşılaştığında onu çözebilmek amacıyla deneyeceği yolları ini ve bu yolları düşünürken ne hissettiğini anlayabilmek için duygu durumunu incelenip ele alıp almadığını ölç.ülmesidir.

Düşünen yaklaşım: Kişinin bir sorunla karşılaşığında problem durumunu anlamak amacıyla girişimlerde bulunup bulunmadığını ve bu konuya yönelik tüm bilgileri değerlendirip değerşendirmediğinin ölçülmesidir.

Planlı yaklaşım: Kişinin bir problemin çözülmesiyle ilgili, sadece o problemin üzerine durup durmadığının ölçülmesidir.

Aceleci yaklaşım: Bireyin bir problemle karşılaştığında onu çözmek için üzerinde fazla kafa yormadan, aklına ilk gelen fikire göre hareket edip etmediğinin ölçülmesidir (Savaşır ve Şahin, 1997).

Faktör yükü $0.32-0.83$ arası değişim gösteren envanterin güvenirlik katsayısı 0.74 olarak bulunmuştur. Envanterin üç boyut (faktörden) oluşan özgün yapısı orijinal olarak korunmuştur ve $\mathrm{N}$ iç tutarlığını tespit etmek amacıyla hesaplanan Cronbach Alpha güvenirlik katsayısı 0.74 olarak belirlenmiştir. Güvenirliği değerlendirmek için Spearman Brown iki yarı güvenirlik-testi yapılmış ve katsayı 0.80 bulunmuştur. Tüm bu sonuçlar ölçeğin güvenilir olduğunu ortaya koymaktadır.

\section{Epistemolojik (Bilgibilimsel) Inanç Ölçeği}

Schommer (1990), epistemolojik inançların yalnızca bilgi, zeka ya da öğrenme gibi tek bir boyut açısından ayrı ayrı ele alınmasının yetersiz bir yaklaşım olduğuna dikkat çekmiş ve epistemolojik inançların tüm bu boyutları içine alan çok boyutlu bir yapı biçiminde, yani bir inanç sistemi olarak düşünülmesi gerekliliğinden yola çıkarak kapsamlı bir Epistemolojik İnanç Ölçeği geliştirmiştir. Dört faktörlü yapıya sahip ölçekte, likert tipi 63 madde yer almaktadır (Schommer, 1998; Schommer, 1990). Ölçekteki maddelerin 35'i olumlu (+), $28^{\prime} \mathrm{i}$ ise olumsuz (-) yönde kodlanmaktadır. Ölçeğin ilk faktörü Öğrenme Yeteneği Doğuştandır (Innate Ability) adını, ikinci faktör Bilgi Basittir (Simple Knowledge) adını, üçüncü faktör Öğrenme Hemen Gerçekleşir (Quick Learning) adını taş dördüncü faktör ise Bilgi Kesindir (Certain Knowledge) adını taşımaktadır.

Schommer'in epistemolojik inanç ölçeği lise ve üniversite öğrencileri ile yetişkinlere kolaylıkla uygulanabilir niteliktedir. Ölçeğin puanlandırıması faktör bazında yapıılığı için, ölçek tamamından elde edilen toplam puanlar değerlendirilmemektedir. Bunun sebebi, ölçeğin her bir faktöründe diğer faktörlerde bulunmayan bağımsız bir boyut ölçümlemesi ve her boyutun öğrenmeye farklı etkilerde bulunuğunun bilinmesidir (Schommer, 1990). Ölçeğin bir faktöründen elde edilen yüksek puanlar, katılımcının o faktöre ait olgunlaşmamış/gelişmemiş (naive) inanca sahip olduğunu, düşük puanlar ise kişinin o faktöre ait olgunlaşmış/gelişmiş (sophisticated) inanca sahipliğini ortaya koymaktadır.

Ölçek, Deryakulu ve Büyüköztürk (2002) tarafından Türkiye'ye uyarlanmıştır. Ölçeğin faktör yapısını belirtmek için faktör analizi yapılmış ve 28 maddenin faktör yük değerinin 0.30'un altında kaldığı ya da birden fazla faktörde yüksek yük değerine sahip oldukları görülmüştür. Bu tür maddeler ölçekten çıkartılmış ve kalan 35 madde için faktör analizi tekrar yapılmıştır. Ölçeğin test - tekrar test güvenirliği .74 olup faktörlerin güvenilirlik katsayıları ise 
.85 - .63 arasında değişim göstermektedir (Schommer, 1993).

Ölçeğin özgün hali, 'Sabit Yetenek', 'Öğrenme Hemen Gerçekleşir', 'Bilgi Basittir' ve 'Bilgi Kesindir' şeklinde dört faktöre sahiptir ve Türkçe uyarlamasında kültürel farklılıklar sebebiyle 'Öğrenmenin Çabaya Bağlı Olduğuna İnanç', 'Öğrenmenin Yeteneğe Bağlı Olduğuna Inanç' ve 'Tek Bir Doğrunun Var Olduğuna İnanç' şeklinde faktörler derecelendirilmiştir. Ölçeğin test tekrar güvenirliği .74, faktörlere ait güvenilirlik katsayıları ise .85 ile .63 arasında yer almaktadır (Schommer, 1993). Ölçeğin Cronbach Alpha iç tutarlık katsayıları faktörler arası sırasıyla;.83,.62, ve .59 olup ölçeğin tamamı için.71 şeklinde bulunmuştur (Deryakulu, Büyüköztürk, 2002).

\subsection{Verilerin Analizi}

Araştırmada uygulanan ölçeklerden elde edilen veriler SPSS 16.0 paket program kullanılarak analiz edilmiştir. Üniversite öğrencilerinin problem çözme ve öğrenilmiş güçlülük puanları ile epistemolojik inanç alt boyutları puanları arasındaki ilişkinin analizinde Pearson Momentler Çarpım Korelasyon Katsayısı Tekniği ve Bootstrap Etki Mekanizması kullanıımıştır. Epistemolojik inanç özelliğinin problem çözme ve öğrenilmiş güçlülük düzeylerini anlamlı düzeyde yordayıp yordamadığı çözümlenmiştir.

\section{BULGULAR}

Araştırmada yapısal model analizinden önce doğrulayıcı faktör analizi yapılarak ölçümsel model değerlendirilmiştir. Epistemolojik inanç, problem çözme ve güçlülük örtük değişkenler olarak tanımlanmıştır. Her değişken için ise Bootstrap Gücen Aralı̆̆ı, korelasyon kullanılmış ve böylece incelenen üçlü değişken ile ölçümsel model ele alınmıştır. Modele ilişkin tablo ve diyagramlar aşağıda sunulmaktadır.

Tablo 1

Epistemolojik inanç, Problem çözme ve Geleceğe Güçlülük Arasındaki ilişkiler ve Betimsel İstatistikler

\begin{tabular}{lcccccc}
\hline & \multicolumn{7}{c}{ Korelasyon } \\
& $\begin{array}{c}\text { Problem } \\
\text { çözme }\end{array}$ & Güçlülük & $\begin{array}{c}\text { Epistemolojik } \\
\text { inanç }\end{array}$ & $\mathbf{X}$ & Çarpıklık & Basıklık \\
\hline $\begin{array}{l}\text { Problem } \\
\text { çözme }\end{array}$ & - & $.40^{* *}$ & $.35^{* *}$ & 48.95 & -1.99 & 1.34 \\
$\begin{array}{l}\text { Güçlülük } \\
\begin{array}{l}\text { Epistemolojik } \\
\text { Inanç }\end{array}\end{array}$ & $.40^{* *}$ & - & & & & \\
\hline
\end{tabular}

$\mathrm{p}<.001$

Tablo 1'de görüldüğü üzere Epistemolojik inanç, Problem çözme ve Geleceğe Güçlülük Arasındaki korelasyonlar ve betimsel istatistiklere göre, üç değişken de normallik koşullarını sağlamaktadır. Korelasyonlar ele alındığında, problem çözmenin güçlülük $(r=0.40 ; p<.001)$ ve epistemolojik inanç $(r=0.35 ; p<.001)$ ile pozitif yönde anlamlı ilişkilere sahip olduğu görülmektedir. Bununla birlikte güçlülük ile problem çözme $(r=0.40 ; p<.001)$ ve epistemolojik inanç $(r=0.45 ; p<.001)$ arasında da pozitif yönde anlamlı ilişkiler olduğu görülmüştür.

Tablo 2

Toplam, Doğrudan ve Dolaylı Etki Değerleri (Bootstrap Güven Aralığı Değerleri)

\begin{tabular}{llll}
\hline \multicolumn{2}{c}{ Yol Katsayı } & \multicolumn{2}{c}{ Bootstrap Etki Mekanizması } \\
\hline Problem çözme & $\begin{array}{l}\text { Epistemolojik } \\
\text { inanç }\end{array}$ & Standart Hata & \%95 Güven Aralığı \\
\cline { 3 - 4 } & & Alt Sınır & Üst Sınır \\
\hline
\end{tabular}




\begin{tabular}{llll}
\hline Yön & & & \\
Güçlülük & $.23^{* *}(05)$ & $.51^{* *}(.07)$ & \\
Epistemolojik inanç & $.28^{* *}(05)$ & & .13 \\
U-DZ-Y & & $.17(.05)$ & .33 \\
\hline
\end{tabular}

Not: ${ }^{* *} \mathrm{p}<.01, \mathrm{U}=$ Güçlülük, DZ = Epistemolojik inanç, $\mathrm{Y}=$ Problem çözme

BSH: Big Data Mining Hackathon

Tablo 2'de regresyon temelli aracılık testi sonuçlarına ait problem çözme ile güçlülük arasında epistemolojik inancın etkisine yönelik bootstrapping katsayı sonuçları yer almaktadır. Veriler incelendiğinde, güçlülük düzeyinin problem çözmeyi (BSH =0.23) ve epistemolojik inancı (BSH = 0.51) doğrusal olarak etkilediği görülmüştür. Bununla birlikte, epistemolojik inancın da problem çözmeyi etkilediği doğrusal olarak etkilediği anlaşılmaktadır (BSH =0.28). Dolaylı etkiler değerlendirildiğinde de, epistemolojik inancın öğretmen adaylarının problem çözme ile güçlülük düzeyleri arasında aracı değişken olarak konumlandığı görülmektedir (bootstrap katsayısı = .17, SH = .05; \%95 GA = .13, .33). Ayrıca aracı değişken olan epistemolojik inancın örneklem grubunda modele dahil edilmesiyle, başlangıçta doğrusal bağıntılı ve anlamlı olan problem çözme ile güçlülük arasındaki ilişkinin anlamsızlaşması sonucu epistemolojik inancın bu etkenler üzerinde tam aracı olduğu ifade edilebilir. ( $\left.c^{\prime}=0.04, p>.05\right)$. Değişkenler arası aracılık modeli Şekil 1'de sunulmuştur. Değerler arası katsayı ise tam ilişkiyi ifade etmektedir.

\section{Güçlülük}

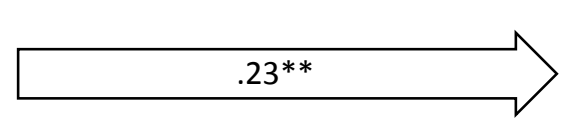

Problem

Çözme

Epistemolojik İnanç
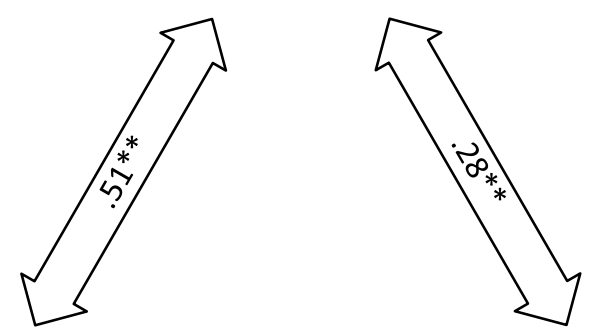

Problem Çözme

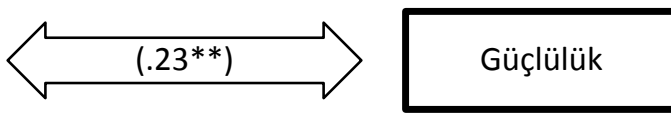


Şekil 1. Problem çözme ve güçlülük düzeyleri ile epistemolojik inanç ilişkisi üçlü yordama aracı etki modeli

Temel aracılık modelinin en önemli özelliği modelde aracı değişkenin bir tane olmasıdır. Araştırmada aracı değişken olarak epistemolojik inanç etki merkezine alınmıştır. Öğretmen adaylarının problem çözme ve güçlülük düzeyleri ile epistemolojik inançlarının ilişkisel rolünün şematik verilerinde görüldüğü üzere güçlülük düzeyleri öğretmen adaylarının epistemolojik inançlarını artırabilmekte ve bu artış neticesinde de problem çözme düzeylerinin de geliştiği görülmektedir. İlişkisel modelde değişken ve varyanslar modelin anlamlılığını ifade etmektedir.

\section{SONUÇ, TARTIŞMA VE ÖNERILER}

Epistemolojik inanç, bireyin bilginin ve öğrenmenin doğasına olan inancı anlamına gelmektedir. Epistemoloji teriminin felsefenin bilgi temelinde olan, bilgi nedir, bilginin kaynakları nelerdir, birey nasıl bilebilir şeklindeki sorulara cevap arayan çalışmaları belirtmesi sebebiyle araştırmada, problem çözme ve güçlülük kavramları arasındaki ilişki incelenmiş ve anlamlı korelasyon bulunduğu görülmüştür.

Epistemolojik inançlar teorik bilgi, motive olma ve öğrenme sürecinin kolaylığını etkileyebilecek önemli bir öğrenen niteliğidir (Pintrich, 2002). Bu sebeple epistemolojik inancın hangi değişkenlerle ne şekilde ilişkili olduğunun belirlenmesi eğitim sektöründe hedeflenen insan profili ve istendik davranışlar açısından oldukça önemlidir. Eğitim, epistemolojik inançları değiştirebilmekte ve şekillendirebilmektedir ancak önemli olan bunu nasıl yapacağı ve neleri etkileyeceğidir (Schraw, 2001). Bu aşamada epistemolojik inançlar ile bireylerin problem çözme ve güçlülük düzeyleri kilit birer kavram olarak ortaya çıkabilmektedir.

Araştırma sonucu, öğretmen adaylarının epistemolojik inançlarının onların problem çözme ile geleceğe yönelik güçlülük düzeyleri üzerinde tam bir etkisinin olduğunu göstermektedir. Çalışmada öncelikle değişkenler arası ilişkiler değerlendirilmiştir. Sonuç olarak problem çözme ile epistemolojik inanç arasında ilişki bulunduğu ve yine epistemolojik inanç ile güçlülük düzeyi arasında ilişki bulunduğu görülmüştür. Araştırmanın diğer bir sonucunda; güçlülük düzeyleri ile problem çözme arasında ilişki bulunmuştur. Bu sonuçlar, literatürde yer alan epistemolojik inanç ile problem çözme ve güçlülük düzeyleri değişkenleri arası korelasyonların yordandığı diğer araştırmalar ile tutarlılık göstermektedir. Kuhn, Dean (2004), Mason, Bromme (2010), eleştirel düşünme ve problem çözmenin epistemolojik olgunluğun etkili bir öğesi olduğunu; White, Frederiksen ve Collins (2009) de üst bilişsel becerilere sahip olabilmek için epistemolojik inancın mutlaka bulunması gereken bir özellik olduğunu belirtmişlerdir. Bu bağlamda araştırmalar epistemolojik inancın salt bir felsefi kavram olmaktan çok öte üstbilişsel metamorfik izlencelerinin olduğunu ortaya koymaktadır.

Yapılan benzer çalışmalar epistemolojik inancın doğrudan problem çözme ve güçlülük düzeylerinin etkileyebilmesinin yanı sıra dolaylı yollardan da bu değişkenlerle bir etki mekanizması içerisinde bulunduğunu ortaya koymaktadır. Buna bağlı olarak çalışmalarda üst biliş yansıtıcı kararlar vermenin eleştirel düşünme ve problem çözme gibi bazı beceriler için kritik ve esasi bir role sahip önkoşul yeterlik olduğunu belirtilmiştir (Dawsonl, 2008; Hofer, 2004). Üstbiliş becerilerin ise epistemolojik inanç ile doğrudan ilişkili olduğu ifade edilmiştir (Schraw, Dennison,1994; Wyre, 2007; Dawsonl, 2008; Başbay, 2013).

Bu çalışmada ise esas amaç olarak adı geçen değişkenler arası ilişkilerin yapılandırılmış bir modelini ortaya konmuştur. Bu modele göre araştırmada öğretmen adaylarının problem çözme düzeyleri ile epistemolojik inanç ve güçlülük düzeylerinin pozitif yönlü anlamlı ilişkilere 
sahip olduğu, epistemolojik inanç ile güçlülük ve problem çözme düzeyleri olan her iki etken ile tam aracı olarak rol oynadığı görülmüştür.

Epistemolojik inanç ile psikolojik sağlamlık üzerine yapılan çalışmalarda epistemolojik inancı yüksek bireylerin psikolojik olarak diğer bireylere oranla daha sağlam yapıda bulundukları bildirilmiş ve epistemolojik inancın, psikolojik sağlamlığı dolayısıyla buna bağlı olarak bireylerin öğrenilmiş güçlülük düzeylerini güçlendiren etkileyici bir faktör olduğu bildirilmiştir (Bilge, Arslan, 2000; Güloğlu, Aydın, 2007; Armstrong, Galligan, 2011). Ayrıca örgütsel güç kaynaklarına yönelik değerlendirmeler, çatışma çözme mekanizmaları ile ilgili bağlantıları da ortaya koymaktadır (Titrek, Zafer, 2009).

Araştırmada aday öğretmenlerin Bilgi Basittir faktöründe gelişmiş düzeyde, Öğrenme Yeteneği Doğuştandır faktöründe orta düzeyde, Öğrenme Hemen Gerçekleşir ve Bilgi Kesindir düzeylerinde ise gelişmemiş inançlara sahip oldukları görülmüştür. Araştırmada epistemolojik inancın alt yeterliklerine ilişkin elde edilen bu sonuçlar benzer araştırmalar ile uyumluluk göstermektedir (Kulcu, 2000; Chai, Khine, Teo, 2006; Erdem, Yılmaz ve Akkoyunlu, 2008;Çağlayan, Mehtap, 2010; Belet, Güven, 2011; Kaleci, 2013; Özdemir, Köksal, 2014; Terzi, Çetin, Eser, 2012). Ancak alanyazında farklı alt boyut yeterliklerine sahip bireylerin bulguları da Yani Bilgi Basittir faktörüne gelişmemiş düzeyde inançlara sahip olunduğunu ortaya koyan çalışmalar da bildirilmiştir (Eroğlu ve Güven 2006; Gürol, Altunbaş, ve Karaarslan, 2010; Köse ve Dinç, 2012; Terzi, Şahan, Çelik, Zöy, 2015). Buradan hareketle çalışma ile tüm alanyazın çalışmaları ile genel sonuç olarak değerlendirildiğinde aday öğretmenlerin bilgisinin kolaylığına inandıkları ve bu konuda nitelikli bilgilere sahip oldukları ancak öğrenmenin doğuştan olduğuna inanmadıkları ve öğrenmenin hızlı gerçekleştiğine inanmadıkları, bilginin ise kesin değil sorgulanabilir nitelikte olduğunu düşündükleri belirtilebilir. Bu açıdan çıkan sonuçlar öğretmenlerin öğrenilmiş çaresizlik düzeylerinin de düşük olabileceğine yani öğrenme ve bilgi edinmeye karşı olumlu tavra sahip olduklarına yorumlanabilmektedir.

Araştırma sonucu ile literatürdeki ilgili araştırmalar değerlendirildiğinde üniversite öğrencilerinin öğrenmenin çabaya bağlı olduğu yönündeki inançlarının orta düzeyde ancak daha da geliştirilebilir olduğu, dolayısıyla çalışmalarının karşıı̆ı̆ını elde etmelerine dair inançlarının artırılması gerektiği de görülmektedir. Elde edilen bu bulgu araştırmada ele alınan Güçlülük değişkenine ile epistemolojik inancın ilişkisinin oldukça önemli olduğunu ortaya koymaktadır. Bu durum araştırmanın epistemolojik felsefede pozitivizm ve pragmatizm paradokslar açısından ümit verici sonuçlarından biri olarak ifade edilebilir.

\section{Öneriler}

Alanyazında ileride yapılabilecek araştırmalarda ise farklı çalışma grupları ile bilginin doğasına ve bilginin edinimine yani öğrenmeye ilişkin inançları geliştiren epistemolojik inançların ahlak, stratejik yaklaşımlar, stres, üzüntü, moral, tükenmişlik gibi benzer faktörlerle yordanması çalışılabilir. Öğretmen adaylarına ya da velilere yönelik ise belirli aralıklarla problem çözme ve güçlülük düzeylerinin takip edilerek seminer, sosyal aktivite, alan çalışmaları gibi faaliyetler ile geliştirilmesi epistemolojik inancın iyileştirilmesi açısından uygun olabilir.

\section{KAYNAKLAR}

Aksu, M. (1989). Problem Çözme Becerilerinin Geliştirilmesi. Kültür ve Turizm Bakanlı̆̆ı ve Orta Doğu Teknik Üniversitesi Problem Çözme Yöntemleri Sempozyumu, 44-54.

Armstrong, A., Galligan, R. (2011). Eq And Psychological Resilience To Negative Life Events. Personality and Individual Differences, 51, 331-336. 
Başbay, M. (2008). Yenilenmiş Taksonomiye Göre Düzenlenmiş Öğretim Tasarımı Dersinde Projeye Dayalı Öğretimin Öğrenme Ürünlerine Etkisi. Yayınlanmamış doktora tezi, Hacettepe Üniversitesi Sosyal Bilimler Enstitüsü, Ankara.

Bedel, E. F. (2012). An examination of locus of control, epistemological beliefs and metacognitive awareness in preservice early childhood teachers. Educational Sciences: Theory and Practice, Special Issue, 3051-3060.

Belet, Ş. D., Güven, M. (2011). Sınıf Öğretmeni adaylarının epistemolojik inançlarının ve bilişüstü stratejilerinin incelenmesi, Kuram ve Uygulamada Eğitim Bilimleri, 11 ç(1), 31-57.

Bilge, F., Arslan, A. (2000). Akılcı olmayan düşünce düzeyleri farklı üniversite öğrencilerinin problem çözme becerilerini değerlendirmeleri. Türk Psikolojik Danışma ve Rehberlik Dergisi, 2(13), 7-18.

Bingham, A. (1998). Çocuklarda Problem Çözme Yeteneklerinin Geliştirilmesi, (Çev. A. F. Oğuzhan), İstanbul: Milli Eğitim Basımevi.

Boz, Y., Aydemir, M., Aydemir, N. (2011). Türkiye'deki 4, 6 ve 8. sınıf ilköğretim öğrencilerinin epistemolojik inançları, ilköğretim Online, 10, 1191-1201.

Chai, C.S., Khine, M.S., Teo, T. (2006). Epistemological beliefs on teaching and learning: A survey among pre-service teachers in Singapore. Educational Media International, $43(4), 285-298$.

Chan, K. (2004). Preservice teachers' epistemological beliefs and conceptions about teaching and learning : Cultural implications for research in teacher education. Australian Journal of Teacher Education, 29 (1).1-13.

Çağlayan, S. H., Mehtap B. (2010). Üniversite bayan futsal takımı sporcularının epistemolojik inançlarının bazı değişkenler açısından incelenmesi, Niğde Üniversitesi Beden Eğitimi ve Spor Bilimleri Dergisi, 4 (1),37-47.

Çakır, Ö. (2009) Çalışma Yaşamında Öğrenilmiş Güçlülük ve İ̧̧ Stresi ile Başa Çıkmada Rolünü Belirlemeye Yönelik Bir Araştırma, 17. Ulusal Yönetim ve Organizasyon Kongresi, 2123 Mayıs, Eskişehir.

Çüçen, A. K. (2005). Bilgi felsefesi. Bursa: Asa Yayınları.

Dağ, í. (1991). Rosenbaum'un Öğrenilmiş Güçlülük Ölçeği'nin üniversite öğrencileri için güvenirliği ve geçerliği. Türk Psikiyatri Dergisi, 2 (4), 269-274.

Dawsonl, T. L. (2008). Metacognition and learning in adulthood, Prepared in response to tasking from ODNI/CHCO/IC Leadership Development Office, Developmental Testing Service, [Online]: Retrieved on 15-February-2012, at URL: .

Derry, S J. (1990). Learning strategies for acquiring useful knowledge. In B.F. Jones-L. Idol (Eds.), Dimensions of Thinking and Cognitive Instruction, Hillsdale, NJ: Lawrence Erlbaum

Deryakulu, D., Büyüköztürk, Ş. (2002). Epistemolojik inanç ölçeğinin geçerlik ve güvenirlik çalış- ması. Eğitim Araştırmaları Dergisi, 2 (8), 111-125.

Dönmez, B., Genç, G. (2006). Genel liselerdeki okul yöneticisi ve öğretmenlerin öğrenilmiş güçlülük düzeylerine ilişkin algıları. Inönü Üniversitesi Eğitim Fakültesi Dergisi, 7, (12), 41-60. 
Erdem, M., Yılmaz, A., Akkoyunlu, B. (06-08 Mayıs 2008). Öğretmen Adaylarının Bilgi Okuryazarlık Özyeterlik İnançları ve Epistemolojik İnançları Üzerine Bir Çalışma. 8th International Educational Technology Conference (IETC), s. 775-779, Anadolu Üniversitesi, Eskişehir.

Eroğlu S. E., Güven K. (2006). Üniversite öğrencilerinin epistemolojik inançlarının bazı değişkenler açısından incelenmesi. Selçuk Üniversitesi Sosyal Bilimler Enstitüsü Dergisi, 16, 295-312.

Garner, R. (1990). When children and adults do not use leaming strategies: Toward a theory of settings. Review of Educational Research, 60 (4), 517- 529.

Garner, R., Alexander, P.A. (1989). Metacognition: Answered and unanswered questions. Educational Psychologist, 24 (2), 143-158.

Gazioğlu, i, E., Demir, i. (2008). Learned resourcefulness, attachment styles, and childhood traumatic experiences: A study on Turkish college sample, European Journal of Social Sciences, 6,(2), 175-187.

Giancoli, D. C. (2013). Physics: Principles with applications (7th ed).Addison-Wesley Pub.

Güloğlu, B., Aydın, G. (2007). Illköğretim 5. sınıf öğrencilerinin öğrenilmiş güçlülük ve otomatik düşünce biçimi arasındaki ilişki. Hacettepe Üniversitesi Eğitim Fakültesi, 33, 157-168.

Gürol, A., Altunbaş, S., Karaarslan, N. (2010). Öğretmen Adaylarının Öz Yeterlik İnançları ve Epistemolojik İnançları Üzerine Bir Çalışma. E-Journal of New World Sciences Academy. Education Sciences, 5 (3), 1395-1404.

Heppner, P.P., Petersen, C.H. (1982). The development and implications of a personal problem -solving inventory. Journal of Counseling Psychology, 29, 66-75.

Hofer, B. (2004). Epistemological understanding as a metacognitive process: Thinking aloud during online searching. Educational Psychologist, 39 (1), 43-55.

Hofer, B. K., Pintrich, P. (2002). Personal epistemology: The psychology of beliefs about knowledge and knowing. Mahwah, NJ: Lawrence Erlbaum.

Jonassen, D.H., Grabowski, BL (1993). Handbook of Individual differences, leaming, and instruction. Hillsdale, NJ: Lawrence Erlbaum.

Kale, N. (2009). Felsefiyat. 1. baskı. Ankara: Pegem Akademi.

Kaleci, F. (2013). Matematik öğretmen adaylarının epistemolojik inançları ile öğrenme ve öğretim stilleri arasındaki ilişki, Eğitim ve Öğretim Araştırmaları Dergisi, 2 (4), 23-32.

Karasar, N.(2006). Bilimsel Araştırma Yöntemi. Ankara: Nobel yayın Dağıtım.

Köse, S. ve Dinç, S. (2012). Fen ve teknoloji öğretmen adaylarının biyoloji özyeterlilik algıları ile epistemolojik inançları arasındaki ilişki, Mustafa Kemal Üniversitesi Sosyal Bilimler Enstitüsü Dergisi, 9 (18), 121-141.

Kuhn, D., Dean Jr., D. (2004). Metacognition: A bridge between cognitive psychology and educational practice. Theory Into Practice, 43 (4), 268-273.

Kulcu, Ö. (2000). Kuramsal Bilginin Oluşumu ve Toplumsal Bilgiye Dönüşümünde Epistemoloji Bilgi Hizmetleri Ilişkisi I. Türk Kütüphaneciliği, 14 (4), 386-411.

Külcü, Ö. (2000). Kuramsal Bilginin Oluşumu ve Toplumsal Bilgiye Dönüşümünde 
Epistemoloji Bilgi Hizmetleri ilişkisi, Iş Türk Kütüphaneciliği 14 (4),386-411.

Locke, J. (1952). An Essay Concerning Human Understanding. Great Books of the Western World, c.35, Chicago.

Main, J.D., Rowe, M.B. (1993). The relation of locus of control orientation and task structure to problem solving performance of sixth grade student 61 pairs. Journal of Research in Science Teaching, 30 (4),401-420.

Mason, L., Bromme, R. (2010). Situating and relating epistemological beliefs into metacognition: studies on beliefs about knowledge and knowing. Metacognition Learning, 5, 1-6.

Mohamed, M. T. \& Habba, M. E. (2013). The relationship between epistemic beliefs and academic performance: are better students always more mature? Canadian Journal of Educational and Developmental Psychology, 3 (1), 158-172.

Morgan, C. T. (1999). Psikolojiye giriş. Ed. H. Arıcı vd., Ankara: Meteksan Yayınları.

Osman, M.E., Hannafin, MJ. (1992). Metacognition research and theory: Analysis and implications for instructional design. Educational Technology Research and Development, 40 (2), 83-99.

Özdemir, i., Köksal N. (2014). The evaluation of elementary scool teachers' epistemological beliefs, Ankara University, Journal of Faculty of Educational Sciences, 47 (1), 301326.

Paris, S.B. ve Myers, M. (1981). Comprehension monitoring, memory and study strategies of good and poor readers. Journal of Reading Behavior, 13 (1),5-22.

Pintrich, P. R. (2000). Educational psychology at the millennium: A look back and a look forward. Educational Psychologist, 35, 221-226.

Raykov, T., Marcoulides, G. A. (2006). A first course in structural equation modeling (2nd ed.).Mahwah, NJ: Erlbaum.

Rodriguez, L. and Cano, F. (2007). The learning approaches and epistemological beliefs of university students: a cross-sectional and longitudinal study. Society for Research Into Higher Education, 32(5) 647-667.

Rosenbaum, M. ve Cohen, E. (1999). Equalitarian Marriages, Spousal Support, Resourcefulness, and Psychological Distress among Israeli Working Women, Journal of Vocational Behavior, 54, 102-113.

Savaşır, I., Şahin, N.H. (1997) Bilişsel-Davranış̧̧ı terapilerde değerlendirme: Sık kullanılan ölçekler. Türk Psikologlar Derneği Yayınları, No.9, Ankara.

Schommer, M. (1990). Effects of beliefs about the nature of knowledge on comprehension. Journal of Educational Psychology, 82 (3), 498-504.

Schommer, M. (1993). Comparisons of beliefs about the nature of knowledge and learning among postsecondary students. Research in Higher Education,34 (3), 355-370.

Schommer, M. (1998). The influence of age and education on epistemological beliefs. British Journal of Educational Psychology, 68, 551-562.

Schommer, M. (1998). The role of adults' beliefs about knowledge in school, work, and everyday life. In M. C. Smith, C. T. Pourchot (Eds.), Adult learning and development: Perspectives from educational psychology. Mahwah, NJ: Lawrance Erlbaum 
Associate. 127-143.

Schraw, G., Dennison R.S. (1994). Assessing metacognitive awareness. Contemporary Educational Psychology, 19, 460-475.

Schraw, G. (2001). Current themes and future directions in epistemological research: A commentary. Educational Psychology Review, 13 (4), 451-464.

Simard, J.C. (2003). Epistemoloji. Bilimname, 2, 13-21.

Siva, A., Dağ, İ. (1997), Rosenbaum'un Öğrenilmiş Güçlülük Ölçeği (Kendini Denetleme Ölçeği) (RÖGÖ) , İçinde Bilişsel Davranışçı Terapilerde Değerlendirme: Sıł Kullanılan Ölçekler. Ed: Işık Savaşır, Nesrin Hisli Şahin, Türk Psikologlar Derneği Yayınları, 9, Ankara.

Siva, A.N. (1991), İnfertilede stresle başetme, öğrenilmiş güçlülük ve depresyonun incelenmesi. Yayımlanmamış Doktora Tezi, Hacettepe Üniversitesi Sosyal Bilimler Enstitüsü, Ankara.

Şahin, N., Şahin, N. H., Heppner, P. P. (1993). Psychometric proporties of the problem solving inventory in a group of Turkish university students, Cognitive Therapy and Research, 4 (17), 379-396.

Taylan, S. (1990). Heppner'in problem çözme envanterinin uyarlama, güvenirlik ve geçerlik çalışmaları. Yayınlanmamış Yüksek Lisans Tezi, A. Ü. Sosyal Bilimler Enstitüsü.

Terzi, A. R., Çetin, G., Eser, H. (2012). The relationship between undergraduate students' locus of control and epistemological beliefs. Educational Research, 3 (1), 030-039.

Terzi, Şahan, Çelik, Zöy, (2015). Öğretmen adaylarının epistemolojik inançları ile eleştirel pedagoji ilkeleri arasındaki ilişki. Eğitim ve Öğretim Araştırmaları Dergisi, 4 (1), 344356

Titrek, O. Erkiliç, A., Süre, E., Güvenç, M., Temür-Pek,N. (2016). The socio-cultural, financial and education problems of international postgraduate students in Turkey. Universal Journal of Educational Research, 4 (12A), 160-166.

Titrek, O., Zafer, D. (2009). İlköğretim okulu yöneticilerinin kullandıkları örgütsel güç kaynaklarına ilişkin öğretmen görüşleri. Kuram ve Uygulamada Eğitim Yönetimi, 15 (60), 657-674).

Trakulphadetkraia, N. V. (2012). Relationship between classroom authority and epistemological beliefs. Journal of International and Comparative Education, 1(2), 71-89.

Ulupınar S. (1997). Hemşirelik eğitiminin öğrencilerin sorun çözme becerilerine etkisi. Yayınlanmamış Doktora Tezi, İstanbul: İstanbul Üniversitesi Sağlık Bilimleri Enstitüsü.

Virieux, R., (1966). L'Épistémologie. Paris, P.U.F. (SUP), s. 3.

White, B. Y., Frederiksen, J. R., Collins, A. (2009) The interplay of scientific inquiry and metacognition: More than a marriage of convenience. In D. Hacker, J. Dunlosky, and A. Graesser (Eds.) Handbook of metacognition in education (pp. 175-205). New York: Routledge.

Wyre, H. S. (2007). Critical Thinking, Metacognition, and Epistemological Beliefs. Unpublished doctoral dissertation, Educational Leadership University Of Phoenix. 
Öğretmen Adaylarının Epistemolojik İnançlarının Problem Çözme Becerileri ve Güçlülük Düzeyleri Üzerine Olan Etkisinin Incelenmesi

Yıldırım, A. Hacıhasanoğlu, R., Karakurt, P. (2007). Hemşirelerin Stresle Başa Çıkmada Bilişsel Stratejileri Kullanma Düzeylerinin ve Etkileyen Faktörlerin Belirlenmesi, Atatürk Üniversitesi Hemşirelik Yüksekokulu Dergisi, 10, 4, 21-29.

Yıldırım, A., Ekinci, M. (2005). Eğitimi hemşirelik olan ve olmayan üniversite öğrencilerinin stresle başa çıkma düzeylerinin karşılaştırılması, Atatürk Üniversitesi Hemşirelik Yüksekokulu Dergisi, 8,(3), 19-29.

Yükselen, A., Çetin, Z. (2007). Okul öncesi dönem çocuklarında akran ilişkileri. Yaşadıkça Eğitim Dergisi 96,4-8. 


\section{SUMMARY}

The epistemological belief is based on variables such as the way in which the individual processes and interprets the information they meet, their level of comprehension, their working strategies, and their ability to think at higher levels have decisive effects. The problem of this research is therefore how the epistemological beliefs on the levels of problem solving and empowerment that may affect the availability of knowledge and knowledge of prospective teacher candidates playing an important role in education constitute the problem.

The most important feature that distinguishes human beings from other living things is obvious. It is through reason that it is a being that can be thought, investigated, questionable. As a result, people need to know and "knowledge" comes out as a product. This information, which is available, allows people to survive and adapt to nature. In time, mankind has used knowledge to orient nature unlike adaptation to nature. Nevertheless, the concept of knowledge has always been thought-provoking for people. It wants to investigate what human knowledge is, whether the right information can be attained, the value of knowledge, its source, its validity, its limitations.

A discipline of philosophy emerged that deals with epistemology, briefly, knowledge-related problems. This discipline, called philosophy of knowledge or epistemology, generally refers to what information is, how and from which way it is derived (Çüçen, 2005). Epistemology, one of the main areas of philosophy, mainly examines the nature, sources, boundaries, conceptual components of human knowledge, and even the possibility of knowledge (Külcü, 2000). Epistemology deals with abstracting from the things that the subject science is aiming at. Thus, epistemology is in no way interested in enhancing information or discovering new experimental spheres such as observing stars or the universe.

The study group of the study is composed of 80 female and 70 male students who are studying at Düzce University Preschool Teaching Department. The 'Rosenbaum Learned Achievement Scale' developed by Rosenbaum (1980) and the 'Problem Solving Inventory' developed by Heppner and Petersen (1982) and 'Epistemological Belief Scale' developed by Schommer (1990) was used for data collection tools.

Epistemological belief is the belief in the nature of the individual and the nature of the individual. The relationship between the concept of problem solving and strength has been investigated and it has been found that there is a meaningful correlation between the concept of epistemology and the concept of problem solving, because the philosophical term is based on knowledge, knowledge, sources of knowledge, and how individuals seek answers.

The study shows that the level of problem solving and empowerment of individuals who have developed epistemological beliefs is also high in a similar direction. At this point, it would be appropriate to support epistemological beliefs and apply treatment to this goal in order to strengthen the problem solving and strength skills about individuals who are particularly exposed to psychologically depressing and jarringly negative situations.

In future studies in the field of literature, it is possible to study the epistemological beliefs that develop beliefs about the nature of knowledge and the acquisition of knowledge, that is learning with different working groups, by similar factors such as ethics, strategic approaches, stress, sadness, morale and burnout. It may be appropriate to improve the epistemological belief by developing activities such as seminars, social activities, field studies, etc., by following the problem solving and strength levels periodically to teacher candidates or parents. 